- Over $90 \%$ of dental practices in Merseyside reported treating people with physical

impairments, learning difficulties and mental health difficulties

- Less than one third of dentists described their practice as fully accessible

- Dentists identified physical barriers, time and access to domicilary equipment as the main

barriers to providing accessible care for disabled people

\title{
Disability Part 2: Access to dental services for disabled people. A questionnaire survey of dental practices in Merseyside
}

\author{
D. M. Edwards ${ }^{1}$ and A. J. Merry ${ }^{2}$
}

\begin{abstract}
This article aims to identify how accessible general dental practitioners thought that their services were and to identify the barriers they face in providing care for disabled people. A postal questionnaire survey was undertaken of all general dental practices in the Liverpool, Sefton, St Helens and Knowsley Health Authorities. Only one quarter of practices described themselves as having full physical access for disabled patients. However, despite this, over $90 \%$ of practices reported treating disabled patients and most were willing to treat more disabled patients. Dentists identified physical barriers, lack of time and the lack of domiciliary equipment as the main barriers to providing care for disabled people. Although dentists were willing to treat disabled patients few dental practices were accessible at the time of the survey. Further work is needed to ensure that dental practices comply with the Disability Discrimination Act.
\end{abstract}

The Disability Discrimination Act (1995) was introduced in 1996 and is being phased in over a number of years. Parts I and II are already in place and Part III will come into effect by $2004 .{ }^{1}$ By this time service providers are expected to have overcome physical barriers to accessing their service. An outline of the Act and its implications for dental practices is given in the first paper of this series. ${ }^{2}$

In September 1999 a wheelchair user complained to her Community Health Council (CHC) that after changing her wheelchair she could no longer get through the door of her dentist's surgery. As a result the $\mathrm{CHC}$ requested a list of accessible practices from Sefton Health Authority. As no list was available, and with the agreement of the Local Dental Committees, the neighbouring Health

${ }^{1 *}$ Director of Public Health, ${ }^{2}$ Specialist Registrar in Dental Public Health, North Liverpool Primary Care Trust, Newhall

Campus, Longmoor Lane, Liverpool L10 1LD

*Correspondence to: Dympna Edwards

E-mail:dympna.edwards@northliverpoolpct.nhs.uk

\section{Refereed Paper}

Received 16.01.02; Accepted 23.05.02

๑ British Dental Journal 2002; 193: 253-255
Authorities of Liverpool, Sefton and St. Helens and Knowsley decided to investigate what services and facilities were available in local dental practices.

Physical access to dental surgeries has previously been reported to be a barrier to disabled patients. ${ }^{3-8}$ In a survey of 107 general dental practices in South London in 1997 Freeman, Adams and Gelbier found that only 55\% had a ground floor surgery. ${ }^{8}$ Fifty six per cent had steps or stairs to the entrance yet only $9 \%$ had a ramp or lift to the entrance. Despite this, $58 \%$ reported that they had wheelchair access to surgeries and $41 \%$ that they had accessible patient toilets. Seventy nine per cent of the practices in Freeman's survey reported treating adults with a physical or learning disability. It has been found that principal dentists who have been in practice for fewer than 5 years and who have attended postgraduate courses are more likely to treat disabled patients. ${ }^{8}$ Dentists' attitudes, lack of training and the time and cost of treating disabled patients have also been reported as barriers to care. ${ }^{3}$

In this study we aimed to identify how accessible general dental practitioners thought that their services were and to identify the barriers they face in providing care for disabled people.

\section{METHODS}

A two-page questionnaire was posted to each dental practice in the Liverpool, Sefton and St Helens and Knowsley Health Authority areas in October 1999. A second copy of the questionnaire was sent to nonresponders in November 1999. Data were entered manually on a database and analysed using SPSS with a chi-squared test of significance.

One hundred and ninety five questionnaires were sent out and 176 were returned. Seventeen questionnaires did not indicate which practice they were from and as these may have been duplicates they were excluded from the analysis. This left a total of 157 returned questionnaires, representing a response rate of $81 \%$. Of these, 67 practices were in Liverpool, 49 in St Helens and Knowsley and 41 in Sefton. Not all practices answered all of the questions and so the figures below do not always add up to the total of 157 . 


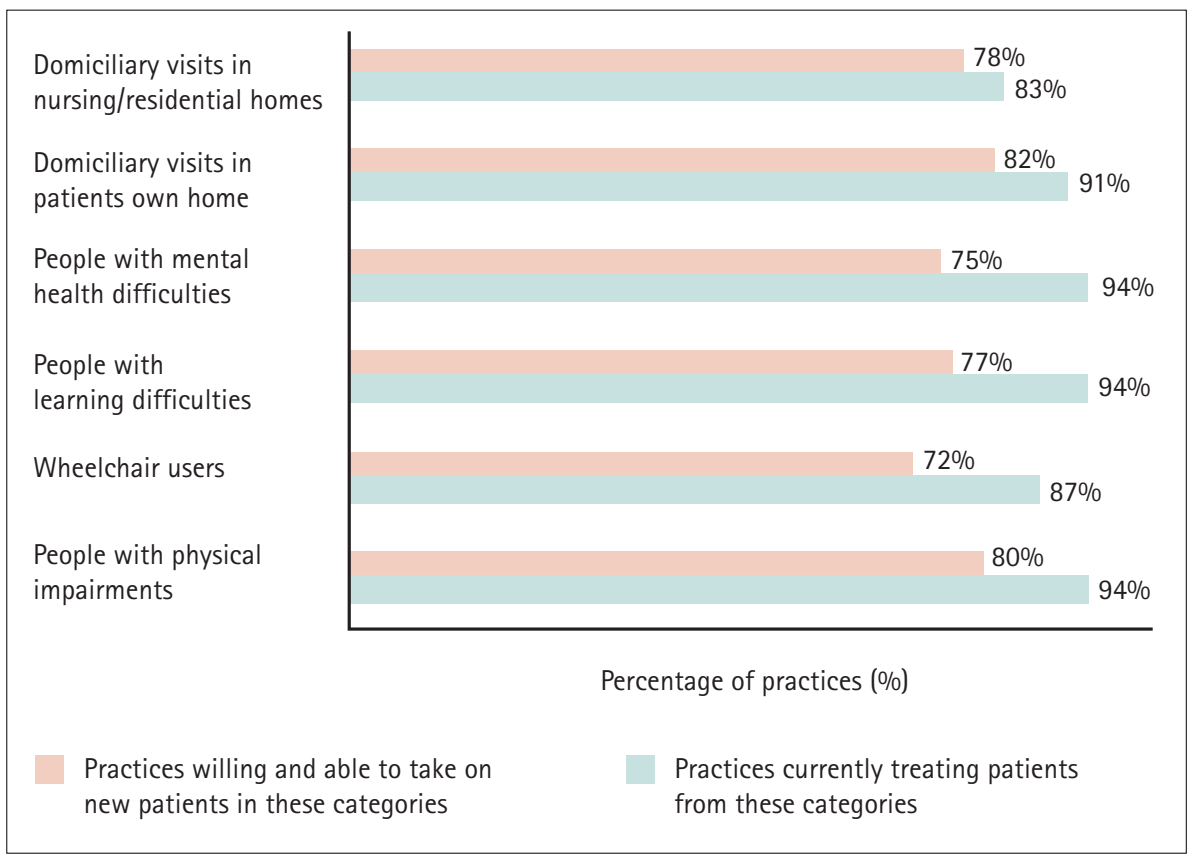

Fig. 1 Availability of dental treatment in GDS practices for disabled patients

\section{RESULTS}

The vast majority of practices reported that they treated patients with physical impairments, learning difficulties or mental health problems (Fig. 1). Slightly fewer practices reported treating wheelchair users. One hundred and twenty five practices (90\%) were accepting new NHS patients and most of these reported that they were able to accept disabled patients (Fig. 1).

More than $80 \%$ of practices provided domiciliary care, with more providing care in patients' homes (91\%) than in nursing homes (83\% Fig. 1). Practices who were already providing domiciliary care were significantly more likely to accept new patients for domiciliary care than those who did not $(P<0.001)$. There were no significant differences between the three districts in the proportion of practices treating different categories of patients or providing domiciliary care.

Dentists were asked to report on how accessible they felt their practice building to be. The questionnaire defined a fully accessible surgery as one on the ground floor without steps or on the first floor surgery with a lift and having adequate door width, adequate circulation space and accessible toilets. One third of practices reported that they had a fully accessible surgery (Fig. 2). Almost half the practices had ground floor access with steps and one eighth had only first floor surgeries without a lift.

Physical access varied by district with a higher proportion of practices in St. Helens and Knowsley reporting full physical access compared with Liverpool or Sefton (Fig. 2, $P<0.2$ ). Although 137 practices reported treating wheelchair users, only 62
- Physical barriers

- Lack of time

- Lack of equipment for domiciliary treatment.
Physical access was the most common barrier identified by those practitioners who were willing to treat patients with physical impairments but were prevented from doing so because patients were unable to access the premises easily. In some cases, ground floor surgery access was available but toilet facilities were inaccessible because these were on the first floor. Dentists reported that lack of access to development grants for dental practices made it difficult to address these problems. Some dentists were concerned that it was difficult to allocate the additional time needed to provide good care for patients with learning disabilities under the current GDS feescale. A few dentists felt that lack of the availability of domiciliary equipment was a further barrier as it prevented them from providing dental care to patients in their own homes.

One hundred and five practices (67\%) expressed an interest in funding to improve accessibility of dental care. They were asked how they would use the funding and given a list of possibilities. Fiftyfour practices (34\%) expressed an interest in a disability access audit. Some practices were interested in buying equipment such as domiciliary equipment (80 practices, $56 \%$ ) or a text phone (46 practices, $29 \%$ ). About half of the interested practices (54 practices, 34\%) wanted to make structural changes such as installing a wheelchair ramp.

\section{DISCUSSION}

This paper describes the situation in a high proportion of dental practices in Merseyside at the time of the study. The high response from dental practices suggests that dentists are aware of and interested in improving access to their services for dis-

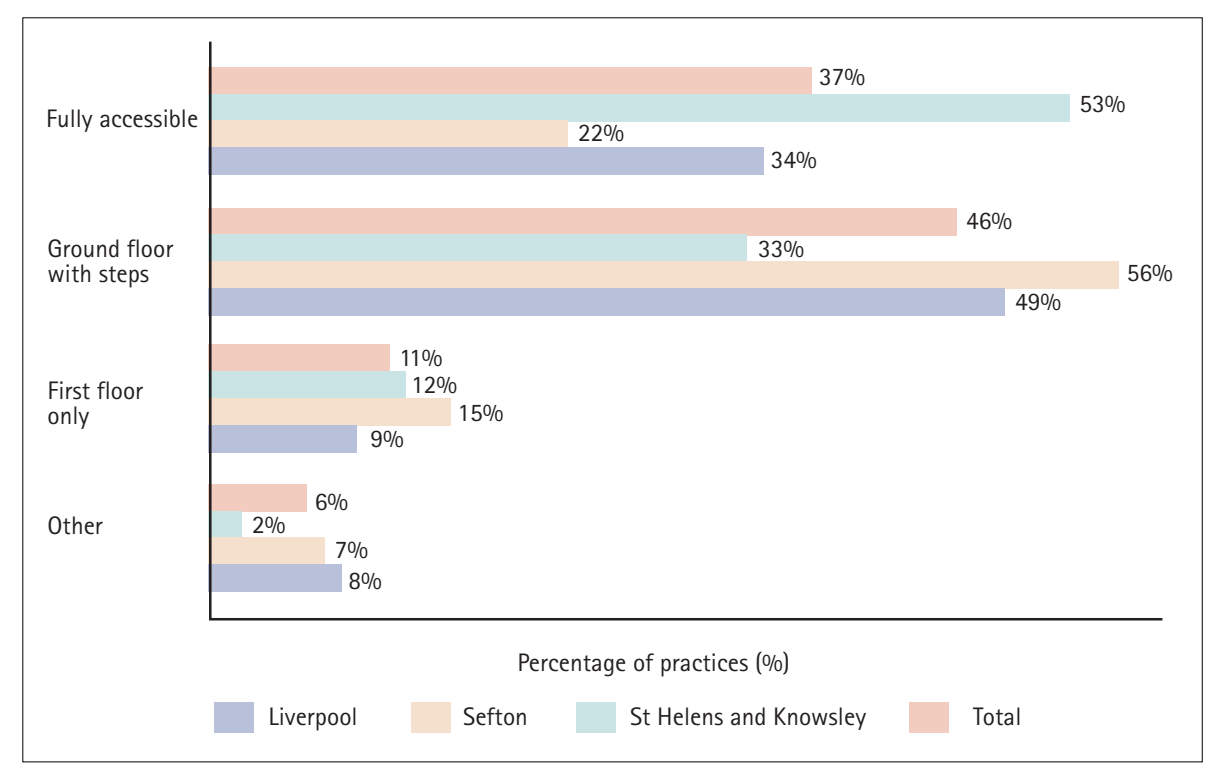

Fig. 2 Reported physical access for general dental practice surgeries by health authority district 
abled people. However, the results of the questionnaire only represent practitioners' views of the accessibility of their services. Patients' views were not sought. It is possible that dentists consider their practices to be more accessible than patients would find them (and vice versa).

The number of practices accepting disabled patients and willing to accept new patients was higher than that found by Freeman et $a l .{ }^{8}$ Unfortunately, the available facilities did not match the practitioners' willingness to treat patients. It is clear that many patients are being treated despite the lack of facilities in situations that are less than ideal.

The problem of lack of time to treat disabled patients that was reported by dentists in this study has also been reported in previous studies. ${ }^{9}$ Some practitioners expressed a willingness to treat their existing disabled patients but were concerned that they did not become a referral centre for patients. Although one dentist reported that disabled people should receive dental care in a hospital or Community Dental Service setting, most practitioners reported a willingness to treat some disabled patients within their practices. Freeman et $a l^{8}$ described a continuum of care across the Community and General Dental Services, with the Community Dental Service providing dental care for patients with more complex needs than the General Dental Service.

The lack of access to improvement grants for practices at the time of the study made it difficult for some practices to improve the accessibility to their practices. Following this study the Merseyside Health Action Zone and three local Health Authorities (Liverpool, Sefton and St. Helens and Knowsley) funded a programme of disability access audits, disability awareness training and grants for practice improvements and equipment. The final paper in this series describes this project.

\section{CONCLUSION}

Few dental practices on Merseyside were accessible at the time of the study and few would comply with the Disability Discrimination Act either under Parts I and II, which are already in force, or under Part III which will come into effect in 2004. Den- tists were willing to see disabled patients but time and facilities made this difficult. Dental practices need to find ways to reduce the barriers to dental care that disabled people face both to improve access for disabled people and to ensure that the practice complies with the Disability Discrimination Act.

1 The Disability Discrimination Act. London: HMSO, 1995.

2 Merry A J, Edwards D M. Disability Part 1. The Disability Discrimination Act (1995) - Implications for dentists. Br Dent J2002; 193: 199-201.

3 Wilson I K. Treatment accessibility for physically and mentally handicapped people- a review of the literature. Community Dent Health 1992; 9: 187-192.

4 Smith J M, Sheiham A. Dental treatment needs and demands of an elderly population in England. Community Dent Oral Epidemiol 1980; 8: 360-364.

5 Pool D. Dental care for the handicapped. BrDent J 1981; 151: 175-177.

6 Finger ST, Jedrychowski J R. Parents' perceptions of access to dental care for children with handicapping conditions. Special Care Dent 1989; 9: 195-199.

7 Kail B P, Silver M M. The dental demands of elderly people living at home in Hertfordshire. Br Dent J 1984; 157: 94-97.

8 Freeman R, Adams E K, Gelbier S. The provision of primary dental care for patients with special needs. Res Primary Dent Care 1997; 4: 31-34

9 Nunn J H, Murray J J. Dental care of handicapped children by general dental practitioners. J Dent Health Educ 1988; 52: 463-465. 